\title{
НЕЙРООФТАЛЬМОЛОГИЧЕСКИЕ НАРУШЕНИЯ У ДЕТЕЙ С ДЕТСКИМ ЦЕРЕБРАЛЬНЫМ ПАРАЛИЧОМ
}

\author{
Маджидова Ё.Н., Абдукадырова И.К.* \\ Кафедра неврологии с детской неврологией и медицинской генетикой \\ Ташкентский педиатрический медицинский институт, Ташкент, Узбекистан
}

Целью работы являлось изучение клинико-неврологических и клинико-офтальмологических особенностей зрительных расстройств у больных с детским церебральным параличом. Было выявлено, что у превалирующего количества детей с детским церебральным параличом наблюдаются зрительные нарушения. В структуре заболеваний зрительных органов лидируют такие заболевания как косоглазие, нистагм и амблиопия.

Ключевые слова: зрительные расстройства, нейроофтальмологические нарушения, детский церебральный паралич.

Детские церебральные параличи - это группа патологических синдромов, возникающих вследствие внутриутробных, родовых или послеродовых поражений мозга и проявляющихся в форме двигательных, речевых, зрительных и психических нарушений. При ДЦП отмечается нарушение координированной деятельности различных анализаторных систем. Патология зрения, слуха, мышечно-суставного чувства существенно сказывается на восприятии в целом, ограничивает объем информации, затрудняет интеллектуальную деятельность детей с церебральным параличом.

Зрительное нарушение - это острота зрения менее 0,3 на лучший глаз с коррекцией и/или поле зрения менее 15 угл. град. Определяя, что такое зрительное нарушение, мы одновременно определяем и круг лиц, нуждающихся в специальном образовании. Зрительные нарушения вызывают у детей значительные затруднения в познании окружающей действительности, сужают общественные контакты, ограничивают их ориентировку, возможность заниматься многими видами деятельности [1].

В настоящее время наблюдается рост заболеваний детей различных форм детского церебрального паралича, при котором отмечается диффузное поражение головного мозга на ранних этапах его формирования [3].

Детский церебральный паралич - полиэтиологическое заболевание, чаще всего начинающееся внутриутробно и продолжающее развиваться в первые годы жизни. Термин
"ДЦП" был предложен 3. Фрейдом (1893) для объединения всех форм спастических параличей пренатального происхождения со сходными клиническими признаками. При ДЦП наблюдается сложная картина неврологических и психических нарушений, не только замедленный темп психического развития, но и неравномерный, диспропорциональный характер формирования отдельных психических функций [2].

При ДЦП нарушения развития носят, как правило, сложную структуру, сочетаются нарушения двигательные, нарушения корковых функций, речи, задержка психического развития. Двигательные нарушения при ДЦП выражаются в поражении верхних и нижних конечностей; страдает мелкая моторика, мышцы артикуляционного аппарата, глазодвигательные мышцы [6].

Дети с ДЦП развиваются в условиях дефицита проприоцептивного отдела двигательного анализатора, что ведет к нарушению развития зрительного восприятия пространства и движения, а также зрительно-моторной координации. Их выраженность и стойкость существенно нарушают качество жизни больного [5,9].

Мозговой органический дефект, составляющий основу ДЦП, возникает рано, в период незавершенного процесса формирования основных структур и механизмов мозга, что обусловливает сложную сочетанную структуру неврологических и психических расстройств (К.А.Семенова, Е.М.Мастюкова, Л.О.Бадалян, Э.С.Калижнюк и др.). В по-

*e-mail: ikbol.abdukadirova@mail.ru 
лиморфной картине психических нарушений при ДЦП наблюдается не только замедленный темп психического развития, но и неравномерный, диспропорциональный характер формирования отдельных психических функций (Семенова, Мастюкова, Смуглин, 1972; Калижнюк, 1987; Ковалев, 1985 и др.).

У большинства больных отмечаются нарушения зрительного восприятия, связанные с недостаточной фиксацией взора, нарушением плавного прослеживания, сужением полей зрения, снижением остроты зрения. Часто встречается косоглазие, двоение в глазах, опущение верхнего века (птоз). Двигательная недостаточность мешает формированию зрительно-моторной координации. Такие особенности зрительного анализатора приводят к неполноценному, а в отдельных случаях к искаженному восприятию предметов и явлений окружающей действительности [6].

Нарушения опорно-двигательного аппарата определяет развитие познавательной сферы детей. Так восприятие пространства рассматривается как результат совместной деятельности различных анализаторов, среди которых особо важное значение имеет двигательно-кинестетический. У детей с церебральными параличами имеет место недоразвитие пространственного гнозиса, что связано с недоразвитием или поражением теменной доли больших полушарий головного мозга и с нарушениями зрительного восприятия $[7,8]$.

Также у детей с ДЦП затруднена перцептивная активность в силу двигательного дефекта: нарушения двигательных функций, а также мышечного аппарата глаз нарушают согласованные движения руки и глаза.

Целью работы являлось изучение клиниконеврологических и клинико-офтальмологических особенностей зрительных расстройств у больных с детским церебральным параличом.

Материалы и методы исследования. На клиническом наблюдении находились 70 больных в возрасте от 2 до 10 лет, леченных Республиканской психоневрологической детской больницы имени К. Курбанова, а также в отделении детской неврологии в Зй городс- кой детской больницы с 2013 по 2015 г.

Для оценки тяжести состояния больных и определения состояния зрительных расстройств у всех больных были проведены клинико-неврологические и клинико-офтальмологические исследования.

Результаты и обсуждения. Нами было обследовано 70 детей, из них 40 мальчиков, 30 девочек, в возрасте от 2 до 10 лет.

Учитывая ведущие этиопатогенетические причины церебральных параличей, все случаи заболевания можно условно подразделить на две большие группы: генетическую и негенетическую.

Анализ этиологических данных выявил, что в 40 случаях заболевания было врожденным из-за различных тератогенных факторов (TORCH инфекции, вредные привычки, прием медикаментов, заболевания матери).

Отдельные болезни или травмы матери во время беременности также могут представлять опасность для развития плода, ведущую к формированию неврологической патологии. Женщины с аутоиммунными антитиреоидными или антифосфолипидными антителами также имеют повышенный риск рождения ребенка с неврологическими нарушениями.

В 50 случаев церебрального паралича у детей вызваны причинами, воздействующими на организм ребенка уже после рождения.

Несовместимость матери и ребенка по группе крови или резус-фактору может привести к билирубиновой энцефалопатии плода (так называемой "ядерной желтухе"), чреватой формированием гиперкинетических или дискинетических синдромов. Профилактикой этого грозного осложнения является рутинный скрининг анти-Rh-антител у резус-отрицательных женщин после каждого рождения резус-положительного ребенка и уровня гемоглобина и билирубина у новорожденного.

Серьезные инфекции, которые влияют на мозг напрямую, такие как менингит и энцефалит, также могут вызвать необратимые повреждения головного мозга, приводящие к стойкому инвалидизирующему дефициту моторики и психики [5]. 
Результаты проведенного клинико-неврологического и клинико-офтальмологического исследования выявили следующие отклонения:

- легкое нарушение зрительных функций, двустороннее снижение остроты зрения от 0,16 до 0,4 с коррекцией; концентрическое двустороннее сужение поля зрения от 25 до $50^{\circ}$ от точки фиксации -27 (40\%);

- умеренное нарушение зрительных функций, снижение остроты зрения в лучше видящем глазу от 0,1 до 0,2 с коррекцией - 20 $(32 \%)$;

- выраженное нарушение зрительных функций, снижение остроты зрения в лучше видящем глазу от 0,04 до 0,09 с коррекцией; центральная абсолютная скотома в $10^{\circ}-19(28 \%)$;

В частности у обследованных групп детей было выявлено:косоглазие - 12 (45\%), гиперметропия - $3(15 \%)$, амблиопия - $3(15 \%)$, близорукость - 4 (20\%), астигматизм - 2 (11\%), нистагм $5(25 \%)$, атрофия зрительного нерва - 2 (10\%).

У обследованных групп детей с ДЦП имеет место своеобразное развитие зрительных ориентировочных реакций. У ребенка с ДЦП на оптический раздражитель возникает притормаживание общих движений. При этом отсутствует двигательный компонент ориентировочной реакции, то есть поворот головы в сторону источника света. У некоторых детей вместо ориентировочных реакций возникают защитно-оборонительные реакции: вздрагивание, плач, испуг.

Дети не в состоянии следить глазами за своими движениями у них нарушена зрительно-моторная координация, нет единства поля зрения и поля действия.

Все это негативно сказывается на форми-

\section{ЛИТЕРАТУРА}

1.Дети с отклонениями развития/сост. Н.Д. Шматко.М.,1997

2.Ипполитова М.В., Бабенкова Р.Д., Мастюкова Е.М. Воспитание детей с церебральным параличом в семье. - М., 1993. 3.Козявкин В.И., Шестопалова Л. Ф., Подкорытов В.С. Детские церебральные параличи. Медико-психологические аспекты, Львів, 1999.

4.Архипова Е.Ф. Коррекционная работа с детьми с церебральным параличом. - М., 1989.

5.Бадалян Л.О., Журба Л.Т., Тимонина О.В. Детские церебральные параличи. - Киев, 1988. ровании образа восприятия, препятствует выработке навыков самообслуживания, развитию предметной деятельности, пространственных представлений, наглядно-действенного мышления, конструирования, а в дальнейшем тормозит усвоение учебных навыков, развитие познавательной деятельности в целом.

Сопутствующие симптомы церебрального паралича зачастую снижают качество жизни пациентов больше, чем основные симптомы заболевания.

К 3-5 годам и ранее могут быть обнаружены нарушения оптико-пространственного запоминания.

У 50-60\% отмечается задержка психического развития, но первичный интеллект сохранен. У 20-25\% детей с ДЦП диагностируется олигофрения.

В качестве примера можно привести следующие статистические данные: около 1/3 больных ДЦП имеют средние и тяжелые интеллектуальные и познавательные нарушения, около 1/3 - легкие нарушения интеллекта и обучения, и только у 1/3 пациентов с церебральным параличом интеллект не поврежден.

Вывод. По результатам нашего обследования было выявлено, что превалирующего количества детей с детским церебральным параличом наблюдаются зрительные нарушения. В структуре заболеваний зрительных органов лидируют такие заболевания как косоглазие, нистагм и амблиопия.

Выраженные клинико-офтальмологические изменения, отмеченные у больных с детским церебральным параличом напрямую коррелируют от тяжести интеллектуальных и познавательных нарушений.

6.Комплексная реабилитация детей с детским церебральным параличом: Методические рекомендации. М. - СПб., 1998.

7.Максимова Н.Ю., Милютина Е.Л. Курс лекций по детской патопсихологии. Ростов н/Д: Феникс, 2000.

8.Психодиагностика и коррекция детей с нарушениями и отклонениями развития / Под ред. В.М. Астапова, Ю.В. Микадзе. СПб.: Питер, 2001.

9.Ehrenkranz R.A., Dusick A.M., Vohr B.R. Growth in the neonatal intensive care unit influences neurodevelopmental and growth outcomes of extremely low birth weight 
infants // Pediatrics. - 2006.- Vol. 117 (4).- P. 1253-1261.

10.Imms C. Children with cerebral palsy participate: a review of the literature // Disabil.Rehabil. - 2008. - Vol. 11/30;30(24).- P.1867-1884.

11.Forssberg H., Eliasson A.C., Redon-Zouitenn C.
Impaired grip-lift synergy in children with unilateral brain lesions // Brain. - 1999. - Vol. 122 (6).-P. 1157-1168.

12.Kolawole T.M., Patel P.J., Mahdi A.H. Computed tomographic (CT) scans in cerebral palsy (CP) // Pediatr.

C. Radiol. - 1989. - Vol. 20 (1-2).- P. 23-27.

\title{
XÜLASO
}

\section{UŞAQ SEREBRAL İFLICİ OLAN UŞAQLARDA NEYROOFTALMOLOJİ DəYIŞ̧iKLIKLER}

\author{
Məcidova Y.N., Abdukadırova İ.K. \\ Daşkənd pediatrik tibb institutu, Daşkənd, Özbəkistan
}

Tədqiqatın məqsədi uşaq serebral iflici olan xəstələrdə görmə pozulmalarının klinik-nevroloji və klinik-oftalmoloji xüsusiyyətlərinin öyrənilməsi olmuşdur. Məlum olmuşdur ki, uşaq serebral iflici olan uşaqların çoxunda görmə pozulmaları müşahidə edilir. Görmə orqanlarının xəstəliklərinin strukturunda əsas yerləri çəpgözlük, nistaqm və ambliopiya tutur.

Açar sözlər: görmə pozulmaları, neyrooftalmoloji xəstəlikləri, uşaq serebral iflici.

\section{SUMMARY}

\section{NEURO OPHTHALMOLOGICAL DISORDERS IN CHILDREN WITH CEREBRAL PALSY}

\section{Madjidova Yo. N., Abdukadirova I.K.}

Tashkent pediatric medical Institute. Uzbekistan

The aim of the work was to study the clinical neurologic and ophthalmologic clinical features of visual disorders in patients with cerebral palsy. It was found that the prevailing number of children with cerebral palsy, visual impairment are observed. In the structure of diseases of visual organs leading diseases such as strabismus, amblyopia, and nystagmus.

Keywords: visual disturbances, neyroophtalmological disorders, cerebral palsy.

Redaksiyaya daxil olub: 06.10.2015

Çapa tövsiy olunub: 16.10.2015

Rayçi: prof. Şiraliyeva R.K. 